\title{
Límites, negociaciones y conflictos entre Nicaragua y Costa Rica
}

Resumen-Este trabajo presenta los momentos más importantes de la historia de Nicaragua originados por las demarcaciones de la frontera del sur. Abarcan desde los inicios de la colonia hasta el amojonamiento definitivo hecho por el Ingeniero Alexander después del Laudo Cleveland. A lo largo del tiempo, se fueron dando tensiones, negociaciones, proposiciones aceptadas o rechazadas, bravatas, abrazos, tratados, aplazamientos de acuerdos, incumplimientos, frustraciones, alegrías, declaraciones de guerra, y mil cosas más. En medio de todo ello se llegó a un arreglo que culminó delimitando las fronteras entre Nicaragua y Costa Rica, tanto en el Pacífico como en el Atlántico. La recuperación de la historia ayudará a conocer mejor las relaciones entre ambos países, cuyo epicentro siempre ha sido y sigue siendo la frontera en el río San Juan.

\section{Introducción}

El objetivo de este trabajo es presentar algunos de los momentos más importantes de la historia de Nicaragua originados por las demarcaciones de la frontera del sur. Abarcan desde los inicios de la colonia hasta el amojonamiento definitivo hecho por el Ingeniero Alexander, después del Laudo Cleveland. A lo largo de ese tiempo se fueron dando tensiones, negociaciones, proposiciones aceptadas o rechazadas, bravatas, abrazos, tratados, aplazamientos de acuerdos, incumplimientos, frustraciones, alegrías, declaraciones de guerra, y mil cosas más. Pero en medio de todo ello se llegó a un arreglo, que culminó delimitando las fronteras entre Nicaragua y Costa Rica, tanto en el Pacífico como en el Atlántico. Algunas de estas vicisitudes se reflejan en este trabajo, que ayudará a conocer mejor las relaciones entre ambos países, cuyo epicentro siempre ha sido y sigue siendo la frontera en el río San Juan.

\section{Conquista desde Castilla del Oro (Panamá)}

Desde Castilla del Oro, la gobernación de Pedrarias, se descubrieron las actuales tierras de Nicaragua y Costa Rica. En 1523, Andrés Niño, por mar, descubrió el entorno de Corinto y el Realejo; Gil González, por tierra, el istmo de Rivas. Más tarde, Pedrarias envió a Hernández de Córdoba, quien fundó las ciudades de Bruselas, Granada y León e inició la colonización.

Para Pedrarias, lo conquistado pertenecía a su gobernación. Sin embargo, Gil González, debido a una real capitulación, abogó por la futura gobernación y regresó desde la Española, desembarcando en Honduras. Aquí chocaron sus tropas con las de Hernández de Córdoba y las de 
Hernán Cortés. Gil fue hecho prisionero, llevado a México y enjuiciado en España. Libre del juicio, el rey lo nombró gobernador de Nicaragua, pero murió, en 1526, sin tomar posesión del cargo.

Como Hernández de Córdoba trató de separarse de la jurisdicción de Pedrarias, éste vino a Nicaragua a arreglar la situación. Capturado Córdoba, fue juzgado y degollado en León, en 1526, quedando Pedrarias sin contrincantes. Pero, casi de inmediato los reyes nombraron gobernador de Castilla del Oro a Pedro de los Ríos, en lugar de Pedrarias.

En 1527, el gobernador de Honduras, López de Salcedo, y el nuevo gobernador de Castilla del Oro se disputaron Nicaragua. León y Granada, deseosas de tener un puerto en el Atlántico, se inclinaron por Salcedo. Pedro de los Ríos, derrotado, se retiró a Panamá. Entonces los vecinos de León y Granada solicitaron ante el rey la demarcación de esta gobernación y suplicaron que fuera "desde el golfo de San Lucas hasta Guatemala»' ${ }^{1}$ Pero ya la corte había nombrado a Pedrarias como gobernador de Nicaragua, aunque aquí lo ignoraban.

\section{Limites de Nicaragua en tiempos de Pedrarias}

Nombrado en 1527, Pedrarias asumió el cargo en 1528. La nueva provincia limitaba por el Caribe con la Veragua de Nicuesa y sus límites con Castilla del Oro eran inciertos, porque aún la corona no había respondido a la solicitud de granadinos y leoneses.
Pedrarias, en enero de 1529, ponía su frontera en Cuchiras (Mapa 1).

MAPA $N^{o} .1$

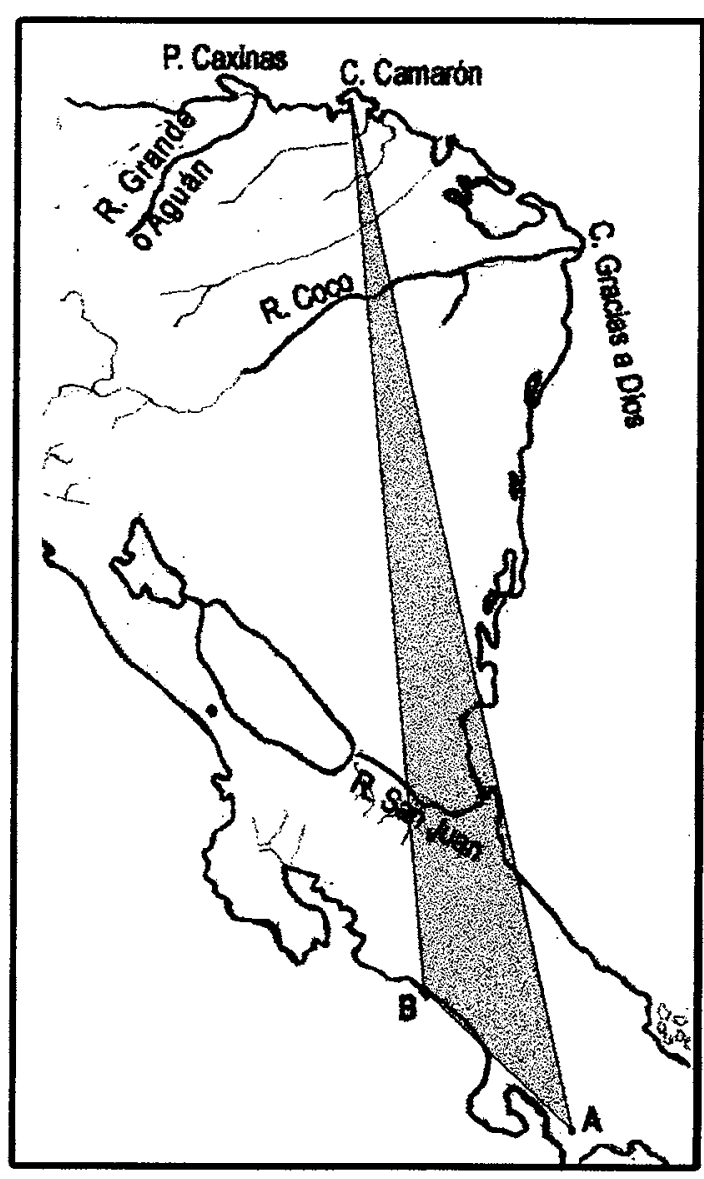

A: Cuchiras, según P.J. Chamorro B: Cuchiras, según Fernández Guardia Según uno u otro viariaba la provincia de Nicaragua

Pero, el 21 de abril del mismo año, la corona fijó la línea divisoria en «los términos y jurisdicción» de Bruselas. No obstante, seguía incierta su demarcación, pues una cosa era la villa y otra la extensión de sus linderos. Una vez muerto Pedrarias, como los límites seguían imprecisos, el ayuntamiento de León en 1531 volvió a solicitar su demarcación desde el golfo de San Lucas al río Lempa ${ }^{2}$. Luis Fernando Sibaja fija así los límites: a) La península y golfo de Nicoya hasta la villa de Bruselas, eran 
de Nicaragua. b) El territorio del este de Cuchiras, pertenecía a Castilla del Oro. c) La parte central, entre el Golfo de Nicoya y Cuchiras, era, probablemente, de Castilla del $\mathrm{Oro}^{3}$ (Mapa 2).

$\operatorname{MAPA} N^{\circ} .2$

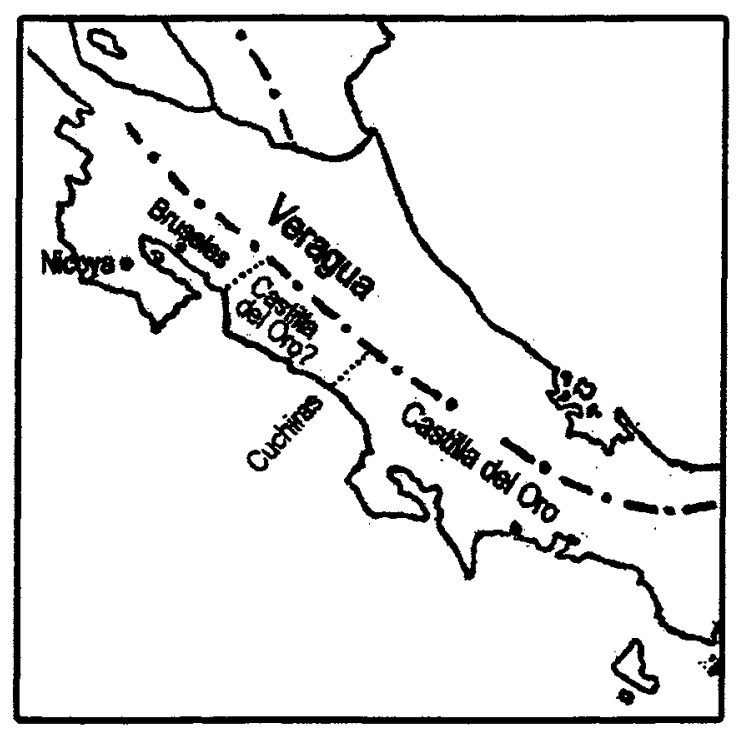

La Veragua Ducal y la Veragua Real o Cartago

En 1530, el Caribe de la actual Costa Rica era de Veragua. Pero en 1534 el rey concedió una capitulación a Felipe Gutiérrez para crear otra provincia, cuyos límites se extenderían desde la de Castilla del Oro hasta el cabo Gracias a Dios. La familia Colón llevó el asunto a juicio. Esto originó la división de Veragua, dejando a don Luis Colón un cuadrado de 25 leguas por lado, entre el río Belén y la laguna Chiriquí ${ }^{4}$ Esta provincia fue La Veragua Ducal.

En 1540, Diego Gutiérrez, hermano de Felipe, recibió un asiento y una capitulación. Podía conquistar desde la Veragua Ducal hasta «el Río Grande», cerca de Punta Caxinas en Honduras. Y se le ordenaba respetar quince leguas del desaguadero del lago, que serían de «la gobernación de Nicaragua» ${ }^{5}$ En 1542, el rey lo nombró gobernador de las tierras conquistadas «de mar a mar». A esta nueva provincia se la llamó La Veragua Real $^{6}$.

Primeros conflictos entre Nicaragua y Veragua Real o Cartago

Aunque desde 1534 Nicaragua era dueña de las costas del Caribe entre el Cabo de Honduras y el de Gracias a Dios, el gobernador Contreras se obsesionó por descubrir todo el Desaguadero y tener una salida natural desde León y Granada a la mar del Norte. Se consiguió en 1539. Después, Contreras, ya en la boca del Desaguadero, fundó un poblado para ampliar su provincia. Para su desgracia, allí se enteró de la capitulación de Diego Gutiérrez. Triste y abatido regresó a Granada en 1541.

La cédula en favor de Gutiérrez quitaba a Nicaragua las tierras comprendidas entre los cabos de Honduras y de Gracias a Dios porque Veragua Real se ampliaba hasta «acabar el Río Grande hazia el Poniente, de la otra parte del cabo del Camarón». La cédula también fijaba los límites, tierra adentro, entre Cartago y Nicaragua, en las susodichas 15 leguas a partir del nacimiento del Desaguadero. El resto, incluido el río, era de Veragua. La navegación y pesca eran comunes. Nicaragua podía navegar y pescar hasta el Caribe, y Veragua en las 15 leguas del río y lago de Nicaragua.

Otra cédula de 1541 mandaba a los 
gobernadores de Nicaragua e Higueras respetar las tierras de Gutiérrez so pena de «diez mil castellanos de oro», de otros bienes y de ser tenidos por traidores. Y, si estaban dentro, debían salir ${ }^{7}$. El asunto limítrofe llegó a la corte. Gutiérrez acusó a Contreras de entrar por el río en su jurisdicción y solicitó al monarca su salida $^{8}$. La petición citaba un documento, donde se afirmaba que Contreras no tenía derecho sobre el río porque el rey podía dárselo a otro «como se os abia dado a vos, sabiendo que era ya descubierto, como con esta va claro» ${ }^{9}$.

Contreras alegó contra Gutiérrez. La corona desechó su petición e insistió en la justa sentencia y en la obligación de respetarla. Siguió alegando y logró que el rey, el 9 de abril de 1541, refrendara sólo parcialmente un auto del $16 \mathrm{de}$ marzo que autorizaba a Diego Gutiérrez a «poblar y repartir en la costa de ambas partes del dicho Desaguadero», aún en tierras descubiertas por Contreras. Sin embargo, debía respetar los poblados ya repartidos por éste. Y además, consiguió que dejaran de ser comunes las aguas de las quince leguas del Desaguadero y del lago, en las que ya no podía entrar Gutiérrez ${ }^{10}$.

Limites entre Nicaragua y Costa Rica en el Siglo XVI

\section{a) Limites entre 1540 y 1573}

Por la cédula de 1540 la Veragua Real se extendió de mar a mar y Nicaragua dejó de limitar con Castilla del Oro.

Nicoya siguió perteneciendo a
Nicaragua. Pero variaron los límites y dejaron de serlo "los términos y jurisdicción» de Bruselas (límites de Castilla del Oro y Nicaragua en 1529). Aunque la cédula de 1540 no mencionaba la demarcación exacta, Peralta consideró que se extendía «desde el primer meridiano citado, $82^{\circ} 6^{\prime}$, remontando hacia el noroeste todo el territorio hasta la frontera de Nicaragua, a quince leguas de distancia del lago, hacia las fuentes del río Tempisque» ${ }^{11}$.

La cédula de la audiencia de Guatemala de 1561, nombrando a Cavallón alcalde mayor de Costa Rica, extendía la frontera de Cartago «desde los límites del pueblo de Nicoya de la provincia de Nicaragua, en adelante» ${ }^{12}$. Por tanto, las tierras de Bruselas pasaron a Costa Rica. Probablemente el límite de Nicoya y Bruselas era el río Tempisque, hasta donde se extendió Costa Rica.

Los límites de la Nicoya de Nicaragua seguían imprecisos. Un mapa de Molina, basado en Peralta, partía del punto de las 15 leguas del Desaguadero, y desde él trazaba una línea recta al nacimiento del Tempisque y seguía su curso hasta el Golfo de Nicoya, pero identificaba el Tempisque y el río El Salto (B-D-G). Para Clotilde Obregón el mapa era diferente. Partía del nacimiento del Desaguadero y en línea recta llegaba a las fuentes de El Salto, seguía su cauce hasta confluir con el Tempisque y proseguía hasta el Golfo de Nicoya (AE-G). Si comparamos los mapas, en el de Obregón, Nicaragua ganaba las tierras situadas entre el Tempisque y El Salto y perdía las limítrofes con las 15 leguas del 
Desaguadero y viceversa (Mapa 3 ).

$\operatorname{MAPA} N^{\circ} .3$

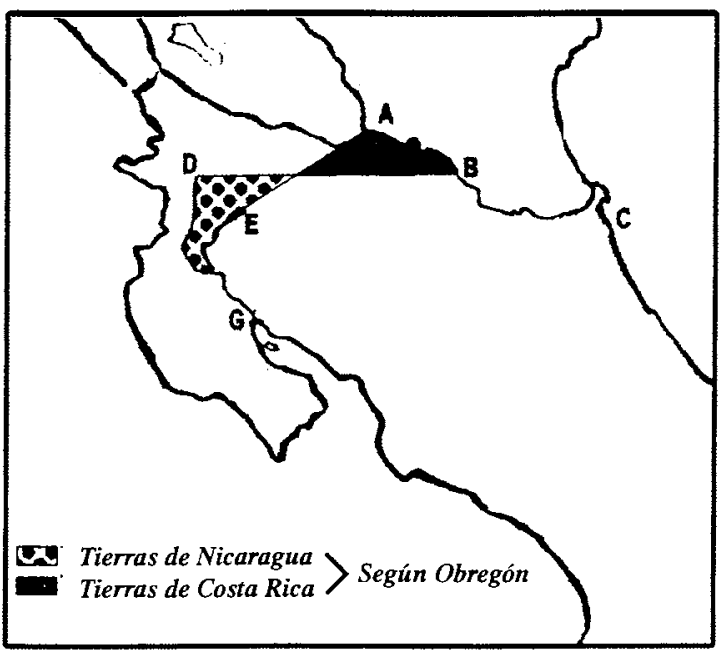

Limites:

Según Obregón: A-E-G

Según Molina: $B-D-G$

Para otros autores, el límite estaba en la desembocadura de los ríos, y no en su nacimiento. En tal caso, Nicaragua ganaba un considerable espacio de terreno. Basta correr en Molina los puntos B-D-G hasta B-G. Y se agrandaba aún más si comparamos los límites dados por Pedro J. Chamorro C-G con los de Molina y Obregón A-E-G (Mapa 4).

$\operatorname{MAPA} N^{0} .4$

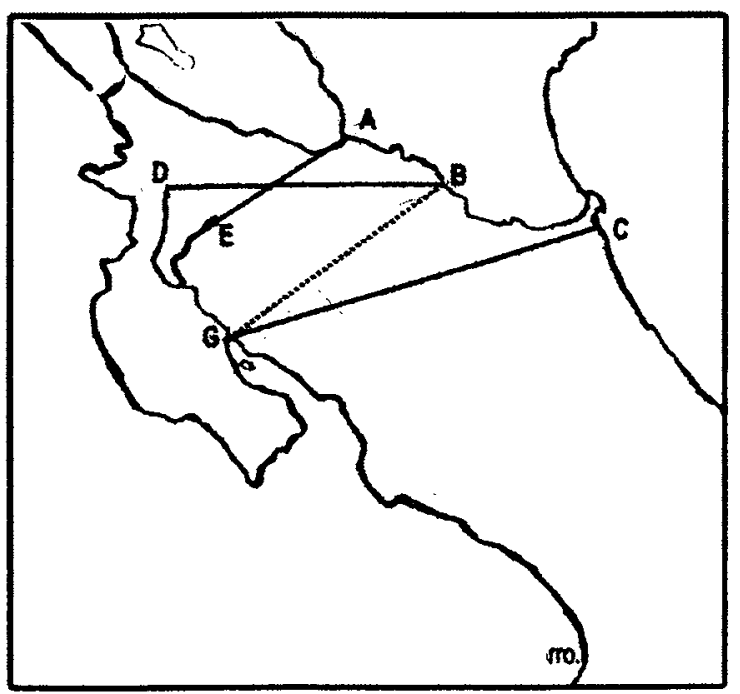

Límites comparativos entre Molina, Obregón y P.J. Chamorro.
En la costa Atlántica, ya se mencionó que Nicaragua perdió las tierras entre los Cabos de Honduras y Gracias a Dios.

Sobre la cédula de 1561 hay división de opiniones. Para Sibaja, se segregó de la Veragua de Cartago el territorio situado entre el Desaguadero y el río Grande, al poniente del cabo Camarón. Pero estas tierras no fueron anexadas a Honduras ni a Nicaragua y formaron la Taguzgalpa, dividida luego, según algunos historiadores, en la Taguzgalpa al norte del río Coco, y la Tologalpa entre el río Coco y el Desaguadero (Mapa 5).

MAPA $N^{\circ} .5$

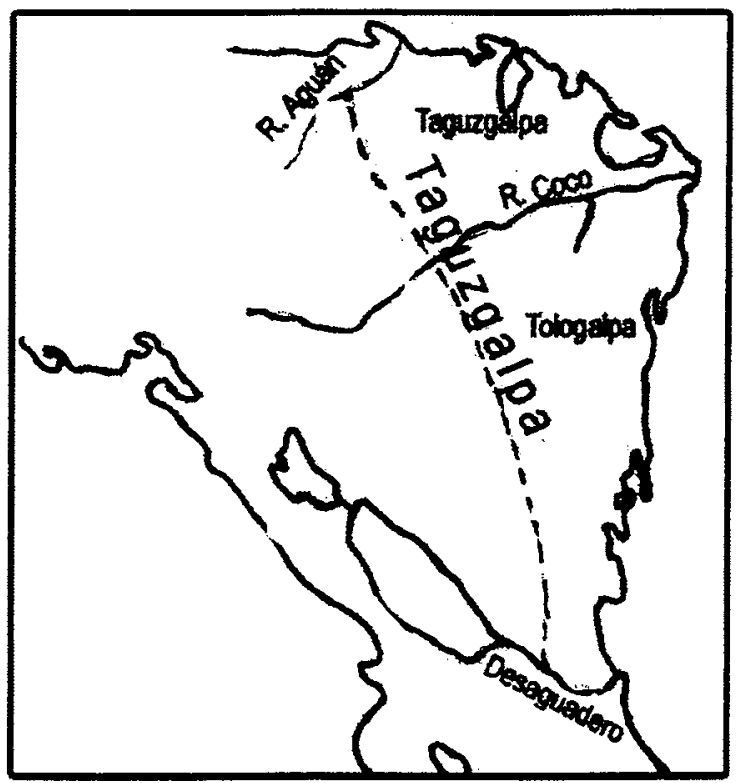

Taguzgalpa y su división

Para Pedro J. Chamorro, la provincia Cartago no cambió las fronteras y lo mismo defendía Peralta cuando afirmaba: «Esta demarcación estuvo vigente desde 1540 hasta $1573 \gg^{13}$.

b) Los límites de 1573

La capitulación de 1573, en favor de Diego de Artieda, enmarcaba su 
conquista "desde los confines de Nicaragua por la parte de Nicoya... (y) desde las bocas del desaguadero, ques a la parte de Nicaragua» hasta la Veragua de Colón ${ }^{14}$. Ahora, la gobernación de Cartago ya no pasaba del Desaguadero o San Juan. Como la preposición «desde» no incluye la palabra referida, se considera que las Bocas eran de Nicaragua.

En las cédulas de 1561 y de 1573 Nicoya era parte de Nicaragua. Costa Rica, según la primera, se extendía «desde los límites del pueblo de Nicoya de la dicha provincia de Nicaragua, en adelante»; y «desde los confines de Nicaragua por la parte de Nicoya», expresaba la segunda. En tal caso el golfo, el Tempisque y El Salto eran los linderos entre Nicaragua y Costa Rica. Pero no se clarificaban las fronteras desde Nicoya hasta el río San Juan o hasta las bocas del Desaguadero, límite fronterizo entre ambas provincias.

Nicoya, Costa Rica y Nicaragua en los Siglos XVII-XVIII

Se ha indicado grosso modo los límites entre la Nicoya de Nicaragua y Costa Rica, en el siglo XVI. Pero desde 1588 Nicoya fue, con ciertos altibajos, independiente. Meléndez Chaverri ${ }^{15}$ lo sintetizó así: $1^{\circ}$.- Desde los inicios de la colonia hasta 1588 Nicoya fue gobernada por Nicaragua. $2^{\circ}$.- Entre 1588 y 1593 fue independiente de Nicaragua y de Cartago. $3^{\circ}$.- Entre 1593 y 1602 estuvo agregada a la provincia de Costa Rica. $4^{\circ}$.- Desde 1602 a 1786 fue plenamente autónoma. $5^{\circ}$.- En 1786, con las reformas borbónicas, perteneció a la intendencia de Nicaragua. Por tanto, mantuvo su plena autonomía e independencia casi dos siglos.

Todos aceptaban que el Partido de Nicoya y Nicaragua limitaban en el río La Flor, en el Istmo de Rivas. En cambio, la frontera de Nicoya con Cartago era más imprecisa y giraba en el entorno de los ríos Tempisque y Salto. La imprecisión se constata en los siguientes documentos.

En 1719 el gobernador Diego de la Haya informaba al Rey que la provincia de Costa Rica se situaba entre Veragua Ducal y Nicaragua, y añadía que la ceñía por el sur «el pedazo del pequeño partido de Nicoya». Líneas más abajo expresaba que el río del Salto separaba Nicaragua y Costa Rica y que el río Tempisque (entre B-C) era el límite entre Costa Rica y Nicoya ${ }^{16}$. En 1744 el ingeniero Luis Díez Navarro informaba que los límites de Costa Rica estaban entre «las bocas del Río San Juan hasta el Escudo de Veraguas» y desde «el Río del Salto hasta el de Boruca o Chiriquí Viejo». Y separaba Nicaragua y el partido de Nicoya. Este limitaba al oeste y norte con Nicaragua y el lago y «Por la parte de Oriente, la Jurisdizion de Costarrica; y por la parte del Sr. dh ${ }^{o}$ Mar» ${ }^{I 7}$. Como se observa, para De la Haya la tierra entre el Tempisque y El Salto era de Nicaragua. En cambio, Díez Navarro se la concedía a Nicoya (Mapa 6). 
MAPA $N^{\circ} .6$

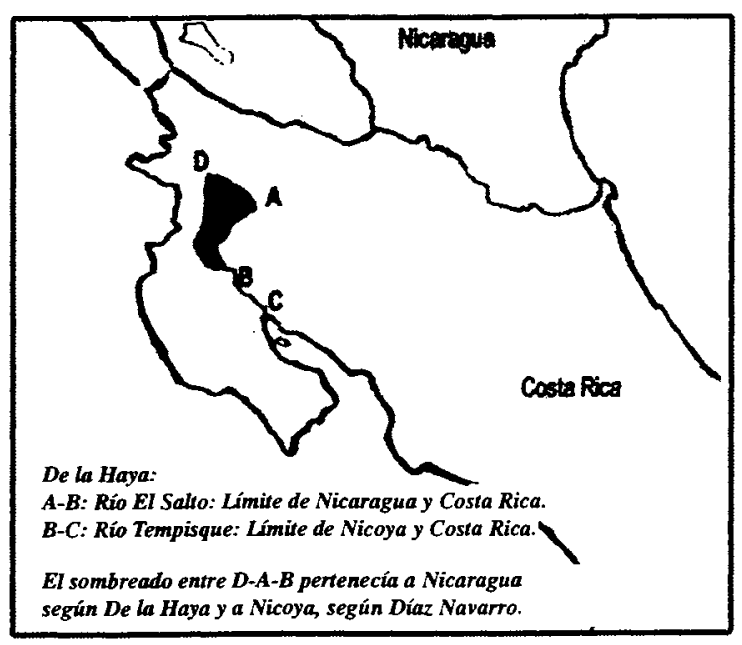

El partido de Nicoya y la intendencia de Nicaragua

Carlos III estableció el régimen de intendencias. La de León, desde 1786, comprendía los partidos de León, Matagalpa, El Realejo, Subtiava y Nicoya, perdiendo este partido su autonomía. Pero al elegir diputados a las Cortes de Cádiz, como Costa Rica tenía pocos habitantes, la audiencia de Guatemala le agregó la población de Nicoya, para fines electorales ${ }^{18}$.

\section{De la independencia al decreto federal de 1825}

De la independencia al tratado de Masaya de abril de 1823

Centroamérica se separó de España en 1821. Luego se anexó a México. En Nicaragua hubo problemas entre la conservadora León y la republicana Granada. Los conflictos y guerras debieron concluir cuando León firmó el Acta de la Orfandad y se declaró republicana, en abril de 1823. Pero el
Tratado de Masaya, en vez de crear una unidad, se convirtió en base permanente de desunión por la supervivencia de los dos gobiernos.

\section{Nicoya, León y Granada}

Nicoya pertenecía a la intendencia de León, juró la independencia y se anexó a México $^{19}$. En 1822, por ciertas tensiones, se separó de León y se unió a Granada. El poblado de Santa Cruz manifestó su disconformidad con la actitud nicoyana.

Al caer el imperio de México, la máxima autoridad política de Centroamérica, Vicente Filísola, en el decreto del 29 de marzo, retomó los principios políticos del acta de la independencia de tener diputados, elecciones y una constitución. Al decreto anexó una «Tabla para facilitar la elección de diputados y suplentes para el Congreso de las Provincias Unidas de Guatemala». En ella aparecía el partido de Nicaragua (Rivas) integrado por Rivas, San Jorge, Ometepe, Nicoya y Guanacaste; separaba Nicoya de Granada y la unía a Rivas. Y, por voluntad de Filísola, Santa Cruz y el Guanacaste, siempre fieles a León, también tuvieron que unirse al Partido de Nicaragua.

La decisión de Filísola de votar así duró muy poquito porque en el artículo $6^{\circ} \mathrm{del}$ tratado de Masaya quedaron en vigencia los gobiernos de León y Granada y cada pueblo podía unirse libremente a cualquiera de los dos. Como consecuencia de esta libertad, Nicoya volvió a unirse a Granada. El Guanacaste, como antes, permaneció fiel a León. 
Rivas se inclinó por Granada y posteriormente se pasó a León, el 8 de julio de 1823. Esta actitud originó que el granadino Cleto Ordóñez atacara Rivas.

Todos estos vaivenes originaron divisiones en Nicaragua y se extendieron a la península de Nicoya. Rivas, el Guanacaste y Santa Cruz estaban con León; Nicoya, con Granada.

La misión diplomática de don Mariano Montealegre

Don Mariano Montealegre de Costa Rica llegó a León cuando Rivas se estaba uniendo a esta ciudad. Firmó sendos tratados con Granada y León. Tanto el artículo 8 del firmado con Granada, como el 12 del subscrito con León ${ }^{20}$, favorecían a Costa Rica. El primero, porque el gobierno granadino se comprometió a apoyar cualquier gestión que, ante la Asamblea Constituyente, hiciera el de Costa Rica para anexar el partido de Nicoya. Sin contar con el Guanacaste y Rivas, Granada prefería que Nicoya, si se separaba de ella, se uniera a Costa Rica; a León, nunca. En el artículo 12 del tr : ado con el gobierno leonés, éste se inclinó ante la propuesta costarricense y dejó en manos de la futura Asamblea lo que él debía defender. Según Miguel Angel Alvarez, se había «aceptado en principio, el desmembramiento del territorio nicaraguiense $»^{21}$.

Las Constituciones y los límites de los Estados

La República Federal nació el 1 de julio de 1823. Su Constitución de 1824 expresaba que los estados de Costa Rica, Nicaragua, El Salvador, Honduras y Guatemala componían la República, pero no determinaba los límites entre ellos. De manera muy imprecisa decía que «la demarcación del interior de los estados se hará por una ley constitucional con presencia de los datos necesarios» (Art'. 7).

Las constituciones de Costa Rica y Nicaragua de 1825 y 1826 fijaron sus límites. Según la de Costa Rica, su territorio se extendía «por ahora de oeste a este desde el río del Salto que lo divide del de Nicaragua... siendo sus límites en el del norte la boca del Río de San Juan...» (Art. 15). La de Nicaragua expresaba que limitaba con «el estado libre de Costarrica» (Art. 2). En la costarricense ese "por ahora» indicaba el deseo de hacer oficial la posesión del partido de Nicoya anexado a Costa Rica en 1824. Además interpretaba que la división territorial, por «las bocas del desaguadero», estaba en el San Juan y no en el Colorado.

Sucesos en Nicaragua: la guerra civil de 1824-182.5

La Guerra de Nicaragua. de 1823 a enero de 1825, creó enorme inseguridad. La Asamblea Constituyente del Gobierno Federal envió a José Justo Milla como pacificador, pero fracasó Las tensiones entre los dos incipientes partidos crecieron. Los fiebres apoyaban a Ordóñez; los serviles y el clero, a Sacasa. Los fiebres dominaban León, Granada, Masaya y otros pueblos; los serviles tenían su base social en Managua, San 
Felipe, El Viejo, Rivas, Jinotepe, Juigalpa y Chinandega. Hubo hasta cuatro juntas gubernativas simultáneas. Ordóñez controlaba las de León y Granada. Las de Managua y El Viejo se unieron en la lucha contra Ordóñez.

Tras el fracaso de Milla, llegó el coronel Manuel de Arzú y también fracasó. En enero de 1825 vino el General Manuel José Arce y logró lo que no consiguieron ni Milla ni Arzú. Sacó del escenario político al obispo García y Jerez y a Cleto Ordóñez para quien negoció un puesto en el ejército como inspector general de las armas de Centroamérica ${ }^{22}$. El país encontró la paz, muy transitoria.

La anexión de Nicoya y Santa Cruz a Costa Rica: 1824

La junta gubernativa de Costa Rica se sirvió de esta guerra para invitar a Nicoya, Santa Cruz y Guanacaste a anexarse a ella. Insistió en las ventajas económicas, políticas y sociales que les acarrearía su unión. Era un momento muy sugestivo para cuantos tenían intereses en peligro o para quienes les importaba más vivir en paz que en la agitada Nicaragua. Esta situación influyó en el ánimo de los habitantes de Nicoya y Santa Cruz, los que proclamaron su unidad con Costa Rica, en 1824. Veamos el proceso:

La municipalidad de Nicoya firmó su anexión el 25 de julio de 1824. Sin embargo, el día 4 del mismo mes, el ayuntamiento, en cabildo abierto, daba a conocer el rechazo a «la invitatoria de la provincia de Costa Rica» del 5 de 30 marzo. Decía que después «de bien meditado» el asunto, se acordó no alterar la demarcación antigua del partido, a no ser que la Asamblea Federal Constituyente determinase otra cosa más conveniente. Y agradecía a Costa Rica su preocupación por «este partido que no puede ser disidente ${ }^{23}$. No obstante, 20 días después, firmó el acta de su separación de Nicaragua y de su anexión a Costa Rica.

La municipalidad de Santa Cruz no dependía de la de Nicoya desde mayo de 1824. Y como podía libremente decidir, optó por anexarse a Costa Rica en el acta del 27 de julio. Sin embargo, los pobladores del barrio de la Costa no la aceptaron. El 8 de agosto se ratificó la anexión y en su acta se enfatizó la situación trágica de Nicaragua (guerra entre Ordóñez y Sacasa, divisiones políticas...) como la causa fundamental que impulsaba a la municipalidad a «apartarse de los lugares en que cada día se aumentan las rivalidades y ruina $»^{24}$.

La población del Guanacaste también recibió la invitación y el ayuntamiento la discutió el 23 de mayo. Unos estaban a favor, pero la mayoría se manifestó inconforme apoyándose en las mutuas relaciones de parentesco, amistad y comercio entre el Guanacaste y Rivas. Prefirieron esperar hasta que "las circunstancias variasen las opiniones» y en la fecha del 25 de agosto seguían aferrados a Nicaragua. Ante esta voluntad popular, el ayuntamiento declinó la invitación ${ }^{25}$. 


\section{El decreto del Congreso Federal y sus consecuencias}

El decreto federal del 9 de diciembre de 1825

Cuando Nicoya y Santa Cruz se unieron a Costa Rica procuraron que este acontecimiento fuese conocido y reconocido por el Gobierno Federal e hicieron peticiones en tal sentido a la Asamblea Nacional Constituyente. La junta de Costa Rica los apoyaba y animaba.

La constitución de Costa Rica de 1825 delimitó sus fronteras con Nicaragua «por ahora» en el río del Salto, pero se sometía al artículo $7^{\circ}$ de la federal: «La demarcación del interior de los Estados se hará por una ley constitucional con presencia de los datos necesarios» (Art. $7^{\circ}$ ). Al disolverse la Constituyente y crearse el Congreso Federal, éste debía fijar los límites de los estados. Nunca lo hizo.

El 9 de diciembre de 1825, el Congreso Federal decretó la anexión del partido de Nicoya a Costa Rica, incluyendo al Guanacaste el poblado siempre fiel a Nicaragua. Para su justificación alegaba que había recibido "reiteradas solicitudes de las autoridades y cuerpos municipales» y que incluso «en la época de los conmociones de Nicaragua» los pueblos de hecho se habían unido a Costa Rica. En vista de ello, decretaba que «por ahora, y hasta que se haga la demarcación del territorio de los Estados, que previene el artículo $7^{\circ}$ de la constitución, el partido de Nicoya continuará separado del Estado de Nicaragua y agregado al de Costa Rica» (art. $\left.1^{\circ}\right)^{26}$. Tal decreto era provisional, no definitivo.

El anterior decreto se apoyaba en la anexión de Nicoya y Santa Cruz del 25 y 27 de julio de 1824. Por eso utilizaba la palabra continuará. Además, pesó en su decisión que el ayuntamiento de Nicoya, en el acta del 4 de julio, aunque rechazó la invitación de Costa Rica, no se negó a aceptarla si la Asamblea Nacional Constituyente algún día lo determinaba. También sopesó el mencionado tratado de Montealegre con León.

\section{Reacción de Nicaragua}

Nicaragua no aceptó la anexión de Nicoya y desaprobó el decreto del Congreso Federal de 1825. Costa Rica presionó sobre los poblados con resultado positivo y Nicoya y Santa Cruz, en 1826 , reconfirmaron la anexión conforme al decreto federal y a la Constitución tica. Pero hubo gente insumisa según lo confirma este hecho: los habitantes de Santa Cruz, en septiembre de 1826 , recibieron una nota del comandante de Nicoya ordenando que todos los rebeldes juraran la independencia el día 17 «prometiendo a los que así lo hicieren verlos como vecinos obedientes, y a los que no, pasar con las bayonetas a toda costa, embargar sus bienes, quemar sus casas y traer. a sus familias a morar a este pueblo" ${ }^{27}$ Con tales disposiciones los disidentes de los barrios de la Costa y la Laguna firmaron el juramento de fidelidad a la constitución. Aunque Nicaragua reclamó 
ante el Congreso Federal y denunció la presión contra la población, todo fue en vano.

Ratificación de la anexión en el año 1828

Entre 1826 y 1829 se desarrolló la guerra Cerda-Argüello. Según el Jefe De La Cerda, el estado de Nicaragua vivía en la ruina, la sangre corría copiosamente y los pueblos y propiedades estaban abandonados y destruidos. Esto fue causa de que personas como Francisco Valenzuela emigraran a «donde en unión de mis amigos pueda pasar tranquilamente los restos de una vida que se me hacía pesada entre el cúmulo de revoluciones y anarquía ${ }^{28}$. En tales circunstancias, Costa Rica se ganaba la simpatía de los nicas ayudándoles con tierras para sembrar. Y en 1828 se renovaron los juramentos de unión como en 1824 y en 1826.

Los intentos de don Dionisio Herrera en 1830

En 1830, en tiempos de Dionisio Herrera, la Asamblea facultó al gobierno de Nicaragua para reclamar ante el Congreso Federal la anulación del decreto del 9 de diciembre de 1825 . Enfatizaba el fin de la guerra, causa del decreto segregacionista, y mantenía la esperanza de arreglar favorablemente la situación fronteriza, componiendo ese decreto temporal. Pensaba que, quitada la causa, se suprimiría el efecto. Todo quedó igual.

Tentativas nicaragüenses en 1834 y 1836 En 1834, en Nicoya se rumoreó que Nicaragua quería retomar esos territorios.
Ante tal noticia los tres municipios ratificaron su unión con Costa Rica. Esta vez la iniciativa partió del Guanacaste, tradicionalmente fiel a Nicaragua, pero en ese momento ya unido a Costa Rica. El $1^{\circ}$ de diciembre, planteó algunos considerandos: las consecuencias de la guerra; la inseguridad en Nicaragua; la inconveniencia de segregarse de Costa Rica; el rechazo al reclamo del gobierno de León de querer que el partido de Nicoya volviera a su seno, y la conveniencia de que el decreto del Congreso fuera «irrevocable». Después invitó a Nicoya y Santa Cruz a gestionar que el Congreso refrendara «su decreto de agregación, haciéndolo extensivo y duradero» hasta que emitiera la ley de demarcación de estados, tal como lo facultaba el artículo $7^{\circ}$ de la constitución de la República ${ }^{29}$. Nicoya y Santa Cruz se adhirieron a la petición, aunque Nicoya quiso dejar claro que ella era «la piedra fundamental de dicha agregación $»^{30}$.

La invasión de Quijano desde Nicaragua, en 1836, produjo efectos negativos. Los tres municipios lo rechazaron ${ }^{31}$.

\section{Los tiempos de las misiones y delegaciones}

\section{La misión de don Francisco María Oreamuno: 1838}

El Estado de Nicaragua, una vez libre, soberano e independiente presentó un proyecto de constitución que, en su artículo $2^{\circ}$, incluía Nicoya entre sus límites. Al conocer el proyecto, el gobierno tico comisionó a Francisco M. 
de Oreamuno para tratar con Nicaragua. El punto 17 de las instrucciones del 26 de julio pedía que Nicaragua concediese a Costa Rica la libertad de navegar por el San Juan y los derechos de exportación de sus frutos por el mismo río. Además, recibió secretamente otras instrucciones. Se le insistía en que no olvidara que a Costa Rica le convenía el Partido de Nicoya, limítrofe con Nicaragua en el río La Flor y que «la vega derecha (del San Juan) aguas abajo hasta el mar, debía reconocerse por de Costa Rica», aunque las aguas correspondieran a Nicaragua (Mapa 7).

\section{MAPA N. 7}

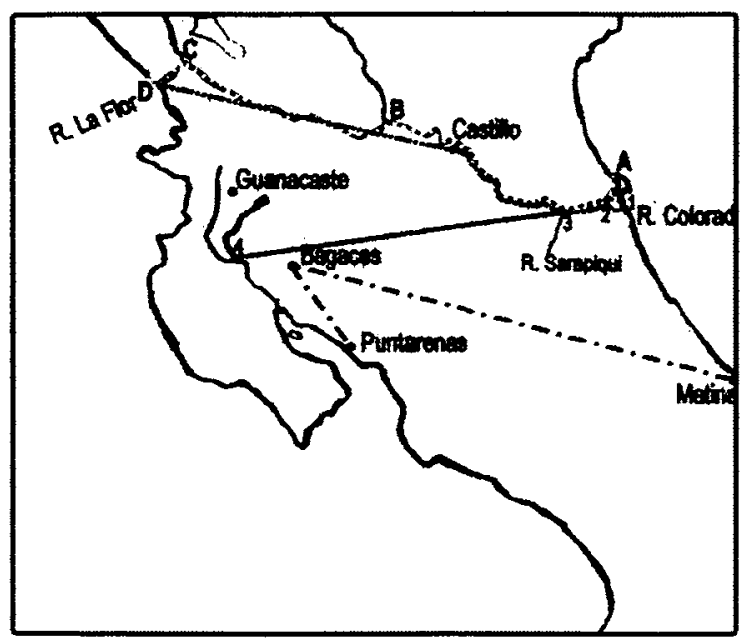

......... Oreamuno y Molina (punto 3)

-...-...Molina (punto 2)

-.....-Juárez

12.s- Juárez (23 de Septiembre)

Se le recomendaba lograr sus objetivos aunque tuviera que ceder «la mitad de toda la deuda, las dos terceras partes y aún el todo», pero sin manifestar señales de interés ${ }^{32}$. Cuando Oreamuno solicitó que «le fuera cedido ad perpetuam el partido de Nicoya $»^{33}$, la petición fue desechada. Luego acentuó el peligro de la presencia de Morazán en Costa Rica y los diputados nicas prefirieron no incluir
Nicoya en Nicaragua y dejaron el artículo $2^{\circ}$ señalando que Nicaragua limitaba por el sudeste con el Estado de Costa Rica. Y añadían: «Las líneas divisorias de los Estados limitrofes serán demarcados por una ley que hará parte de la constitución».

La presencia de Morazán en Costa Rica tensionó las relaciones entre los países y frustró las negociaciones de límites.

La misión de don Toribio Tijerino: 1843 La muerte de Morazán amortiguó las tensiones entre ambos estados y Nicaragua buscó la vía diplomática, para la que fue escogido don Toribio Tijerino.

Siempre había brotes pronicaragüenses en el Guanacaste. Y antes de llegar el Sr. Tijerino a San José, el gobierno de Costa Rica, con la finalidad de frenarlos, publicó un terrible decreto el 24 de diciembre de 1842. El decreto dejaba «ipso facto» fuera de la ley a quien desconociera la autoridad tica. En su punto $2^{\circ}$ expresaba que cualquiera podía quitar la vida a los rebeldes y quien lo hiciera sería gratificado con quinientos pesos del tesoro público y disponía que al asesino se le daría un empleo. En su artículo $3^{\circ}$, declaraba benemérito y prometía un premio de cinco mil pesos al que diera muerte al individuo que por golpe de sedición se apoderase del mando supremo ${ }^{34}$.

Las peticiones nicas del 18 de enero, se reducían a tres: que ambos gobiernos no dejasen entrometerse a otra «administración extraña», alusión a la interferencia inglesa del momento; que 
reconociesen los límites entre ambas, conforme a sus respectivas constituciones de 1825 y 1826 ; y que Costa Rica reconociese también los límites en el río del Salto y devolviese Nicoya a Nicaragua ${ }^{35}$. La delegación tica aceptó la primera petición. Pero, en cuanto a la devolución de Nicoya respondió que el asunto debía someterse de nuevo a la consideración de sus respectivas legislaturas. Las conversaciones fracasaron.

Al llegar a León, Tijerino condenó la presión tica y denunció el envío de un agente para lograr que los departamentos Oriental, Septentrional y del Mediodía se separasen de Nicaragua o desconociesen al gobierno. Costa Rica los apoyaba con armas, pertrechos y dinero. El gobierno tico refutó a Tijerino.

Obsesión tica por el Caribe y los Tratados de Masaya: 1846

En tiempos de José León Sandoval, Costa Rica envió a Nicaragua una delegación con especial encargo de "celebrar los arreglos necesarios relativamente al uso del puerto de San Juan». Se reunió en Masaya con Juan José Zavala y Laureano Pineda.

San Juan del Norte interesaba a Costa Rica porque cada día intensificaba su comercio con Inglaterra. La comercialización del café por Puntarenas dejaba la ganancia a los comerciantes chilenos, y los nacionales buscaron puertos en el Caribe. Pero sólo el de San Juan ofrecía todas las ventajas apetecibles $^{36}$ y este puerto y el río se 34 convirtieron en su obsesión. Como Nicaragua quería solucionar la cuestión de Nicoya, puso la condición de tratar los asuntos limítrofes de manera global. La delegación tica insistía en que sus límites ya estaban fijados por su nueva constitución de 1844 y ofreció una indemnización pecuniaria a Nicaragua. Después, señaló la conveniencia de someter las disputas a un arbitraje.

La delegación costarricense pedía que se reconociese como frontera la margen derecha del puerto y bahía de San Juan del Norte. La nicaragüense aducía que Costa Rica nunca había extendido sus límites hasta el puerto de San Juan y argumentaba que los únicos puertos habían sido el de Matina de Costa Rica y el de San Juan de Nicaragua. Y propuso hacer una repartición exacta y poner la frontera en medio de estos dos puertos y en los desiertos de las tierras despobladas de la vertiente atlántica que «formaban un terreno común y propio de Nicaragua y Costarrica». Según Zavala y Pineda, «las dos antiguas provincias no tenían por aquel lado una demarcación clara que determinase sus límites... (y sí) la tenían al Oeste, entre el Guanacaste y Bagaces». Las últimas palabras aludían al río del Salto, límite entre el Guanacaste y Bagaces (de Costarrica), frontera que Nicaragua consideraba como suya.

Por fin firmaron tres tratados. El segundo trataba de la navegación por el San Juan, pudiendo llevar Costa Rica sus mercancías de acuerdo con las regulaciones que estableciera Nicaragua. En el tercero, sobre límites, las delegaciones llegaron a considerar las 
fronteras en las regiones deshabitadas entre el río del Salto y el Atlántico. Con respecto a Nicoya y Guanacaste, determinaron someterlos a un arbitramento inapelable. Nicaragua ratificó los tres tratados; Costa Rica, ninguno.

Las conversaciones fracasaron. Las circunstancias cambiaban y se preveían conflictos entre Nicaragua e Inglaterra, de los que Costa Rica podía sacar provecho.

La misión de don Felipe Molina: 1848

En 1848, Felipe Molina de Costa Rica llegó a Nicaragua, se reunió con Gregorio Juárez y le formuló tres proposiciones: $1^{a}$.- Que la cuestión limítrofe se acabara por un arbitramento de Inglaterra, Bélgica, Venezuela o Chile. ${ }^{\text {a }}$.- Que el distrito del Guanacaste era de Costa Rica y su límite se trazara con una recta tirada del Castillo Viejo en el San Juan hasta el lugar de La Flor; además, la orilla derecha del San Juan era suya, desde el Castillo a su desembocadura. $3^{\circ}$.- Que ofrecía «compensación pecuniaria», si Nicaragua "quisiere establecer por divisoria, la frontera natural del Rio $S$. Juan desde su embocadura en el atlántico aguas-arriba hasta el punto en que sale del gran lago; $y$ de alli al sur del litoral de éste hasta enfrentar con La Flor, cortando el istmo en este punto» ${ }^{37}$ (ver Mapa 7). Juárez respondió a cada proposición y pidió que se trazase una línea desde Matina pasando por Bagaces hasta Puntarenas $\left(n^{\circ} 2^{\circ}\right)$. No se entendieron y el 21 de septiembre firmaron un tratado de paz, amistad y comercio.

Juárez, el 23 de septiembre, hizo otra proposición de 6 puntos. En el $1^{\circ}$ ponía los límites en la embocadura del Colorado, hacia el Zarapiquí y desde éste a la desembocadura del río del Salto (ver Mapa 7). Arreglado esto, en el $2^{\circ}$ concedía a Costa Rica la navegación por el San Juan para la importación y exportación "con libertad absoluta de todo derecho", pero antes la delegación de Costa Rica debía reconocer Nicoya y el Guanacaste como nicas y renunciar a extender su frontera hasta «la ribera derecha o meridional» del río San Juan. Costa Rica no lo aceptó. Siguieron con otras proposiciones sin llegar a un arreglo.

Juárez criticó la inflexibilidad de una nota de Molina del 1 de octubre pero sin tacto diplomático. En su punto $2^{\circ}$ amenazó "contra el uso que se haga de las aguas del mismo Zarapiquí, y de las del S. Juan deteniéndolas o dándolas un curso diferente al natural, o navegando sobre ellas para transportar frutos $y$ cualquiera artículo de comercio; entendiéndose como una ocupación violenta y como si fuese a mano armada, la que se verifique de otra manera que por el consentimiento de Nicaragua». Esta afirmación era casi una declaración de guerra si se violaba. Afirmaba, no obstante, que el gobierno de Nicaragua quería reconocer los tratados de Masaya del 12 y 14 de diciembre de 1846 .

\section{La intromisión de Inglaterra}

Ya existía gran tirantez entre Nicaragua 
e Inglaterra porque ésta se tomó el puerto de San Juan de Nicaragua el $1^{\circ}$ de enero de 1848. Marcoleta y F. Castellón pidieron a Felipe Molina su apoyo, argumentando que tal usurpación afectaba las fronteras de ambos estados ${ }^{38}$. Molina comentó: «¿Habrá persona con dos dedos de frente, que conociendo los antecedentes espere que el representante de Costa Rica secunde los reclamos de Nicaragua acerca de la Mosquitia?». No le interesaba porque trataba de sacar ventaja de la ocupación británica ${ }^{39}$ en ese poblado. No es de extrañar, pues, que después de romperse las conversaciones entre Juárez y Molina, éste escribiera al vicecónsul inglés solicitándole proteger los intereses costarricenses y británicos en caso de hostilidades entre Nicaragua y Costa Rica ${ }^{40}$.

Estando ya de diplomático en Londres, Molina contactó con comerciantes y capitalistas ingleses para asegurar las fronteras ticas. El maridaje se consolidó cuando, en 1849, Molina, Jorge Fyler del Temple y Juan Carmichael ${ }^{41}$ firmaron un tratado para construir un canal por el San Juan, el lago y el Sapoá. Aquí se descubrió el interés de Costa Rica por el fracaso de las conferencias de 1848 , porque le convenía que la potencia inglesa apoyara semejante proyecto y que las aguas del San Juan y del lago fuesen internacionales. El tratado concedía a los ingleses tierras en litigio «para objetos de colonización». A nadie extrañó que el cónsul Chatfield comunicara al gobierno leonés que había firmado un tratado de amistad, comercio y navegación con Costa Rica y que la defendería contra Nicaragua siempre que fuera necesario ${ }^{42}$.
Los Estados Unidos y el canal

Si Costa Rica se alió con Inglaterra, Nicaragua lo hizo con Estados Unidos. El gobierno nica y la Compañía Americana del Canal de Cornelius Vandervilt firmaron el tratado ZepedaJuárez-White en 1849. La compañía adquirió ciertos derechos exclusivos del canal marítimo y la comunicación por el San Juan y el lago. Además, el contrato en todas sus estipulaciones quedó «bajo la protección y garantía de los Estados Unidos, los que no reconocerán ni permitirán pretensiones algunas por parte de Costa Rica a cualquier porción del territorio de Nicaragua comprendido en dicho contrato ${ }^{43}$, según las palabras de Squier al Gobierno de San José. Esto podía llevar a un enfrentamiento angloamericano.

\section{El Tratado Clayton-Bulwer de 1850}

Inglaterra y Estados Unidos prefirieron negociar y en 1850 firmaron el tratado Clayton-Bulwer ${ }^{44}$, declarando que ninguna de las dos naciones ocuparía, fortificaría ni ejercería «dominio alguno sobre Nicaragua, Costa-Rica, la Costa Atlántica, o parte alguna de Centroamérica». En el art. $6^{\circ}$ ofrecían su mediación para resolver los asuntos limítrofes tico-nicaragüenses. Para las potencias, la paz estaba en función de sus intereses geopolíticos y el gobierno americano presionó a Nicaragua para agilizarla, aunque no lo logró.

La propuesta de Marcoleta: 1852

El diplomático Marcoleta era consciente 
de la lucha de intereses en el entorno del San Juan. Con la fiebre del oro, desde 1848 , el río y el lago habían adquirido nuevas dimensiones sobre todo para Estados Unidos. La importancia geopolítica del San Juan se plasmaba en los tratados entre Inglaterra-Costa Rica, Estados Unidos-Nicaragua y Estados Unidos-Inglaterra. Seguro de que para Nicaragua era más ventajosa la ruta canalera que el partido de Nicoya, Marcoleta trató de cancelar el asunto limítrofe del Pacífico y dar preferencia a la ruta canalera.

\section{El tratado Crampton-Webster de 1852}

Las mismas dos potencias firmaron secretamente el Crampton-Webster en 1852. En su artículo $1^{\circ}$, los ingleses devolvían a Nicaragua el puerto de San Juan. En el $3^{\circ}$, deslindaban los límites entre Nicaragua y Costa Rica con un trazado similar al de Molina de 1848, variando que el río Colorado pertenecía a Nicaragua (Mapa 10).

El tratado fue aceptado por los poderes

MAPA $N^{\prime \prime} .10$

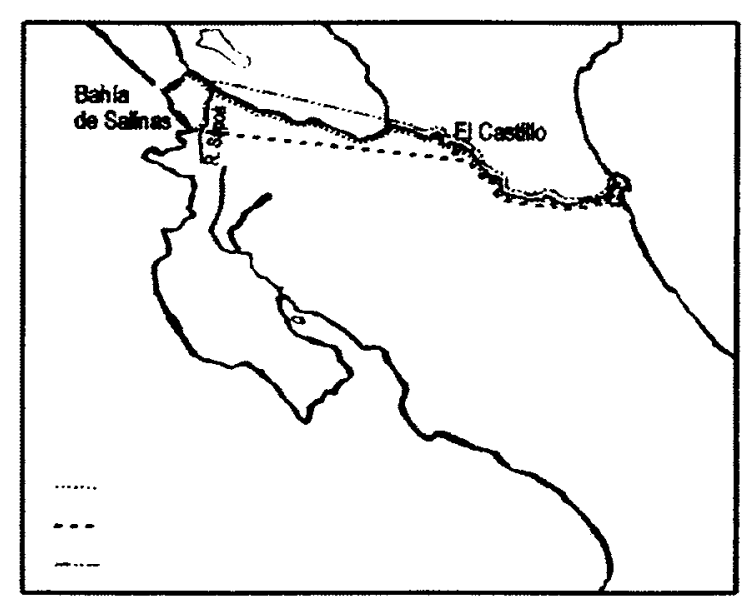

....... Límite según el Crampton - Webster

----- Límite según el Cañas-Juárez

-...-- Trazado canalero según Molina- FylerCarmichael. de Costa Rica. En Nicaragua, a pesar de la presión externa, el director Laureano Pineda defendió los intereses nacionales, inmortalizando la frase de «perecer primero con honor antes que vivir con ignominia» ${ }^{45}$. Envió el tratado al congreso y éste lo consideró lesivo a la soberanía e injerencista en los asuntos internos.

\section{La delegación de don Dionisio Chamorro: 1854}

A pesar del fracaso de las conversaciones Molina-Juárez, los gobiernos volvieron a negociar en San José. Dionisio Chamorro, en la proposición del 10 de enero de 1854 , marcaba la frontera nica desde la bahía sur del Promontorio Descartes en línea recta hacia el río El Refugio $^{46} \mathrm{y}$, al llegar a las dos leguas del lago, seguía "con una línea paralela a la margen del Lago hasta tocar con el río Frío de donde subirá seis leguas por la corriente del río: de este punto, variando de dirección, seguirá una línea paralela al río de San Juan hasta llegar a la Costa del Atlántico» ${ }^{47}$ (ver Mapa 8, A).

La delegación de Costa Rica, el 12 de enero, respondía que su territorio abarcaba «desde la desembocadura del río de San Juan en el Atlántico por la ribera de este río y litoral del lago a la desembocadura del río de la Flor en el Pacífico»(ver Mapa 9, A). El día 16, la delegación dejaba idéntico el trayecto del San Juan pero al tocar el lago, desde el litoral del este, trazaba una línea recta a un punto «sobre el río de la «Flor hasta su desembocadura en el Pacífico» (ver 
Mapa 9, B). Hubo una seria discusión sobre la Tortuga (hoy Cárdenas), y el dominio del Castillo Viejo.

Nicaragua el 7 de febrero mantenía el mismo trazado del 10 de enero hasta tocar el río San Carlos. Y variaba desde ese punto hasta la desembocadura por el Colorado, como se observa en el mapa (ver Mapa 8,B). El día 8 cambió nuevamente los límites. Dejaba el mismo punto de partida de la línea divisoria, la que rectamente iba "hacia la embocadura del río Refugio en el gran Lago»; luego bordeaba el lago hasta llegar al río Frío, por el que subía las ocho leguas $\mathrm{y}$, desde allí, se enrumbaba paralelamente al San Juan; al llegar al Sarapiquí, por la margen derecha bajaba al San Juan y río abajo se dirigía a la boca

$\operatorname{MAPA} N^{o} .8$

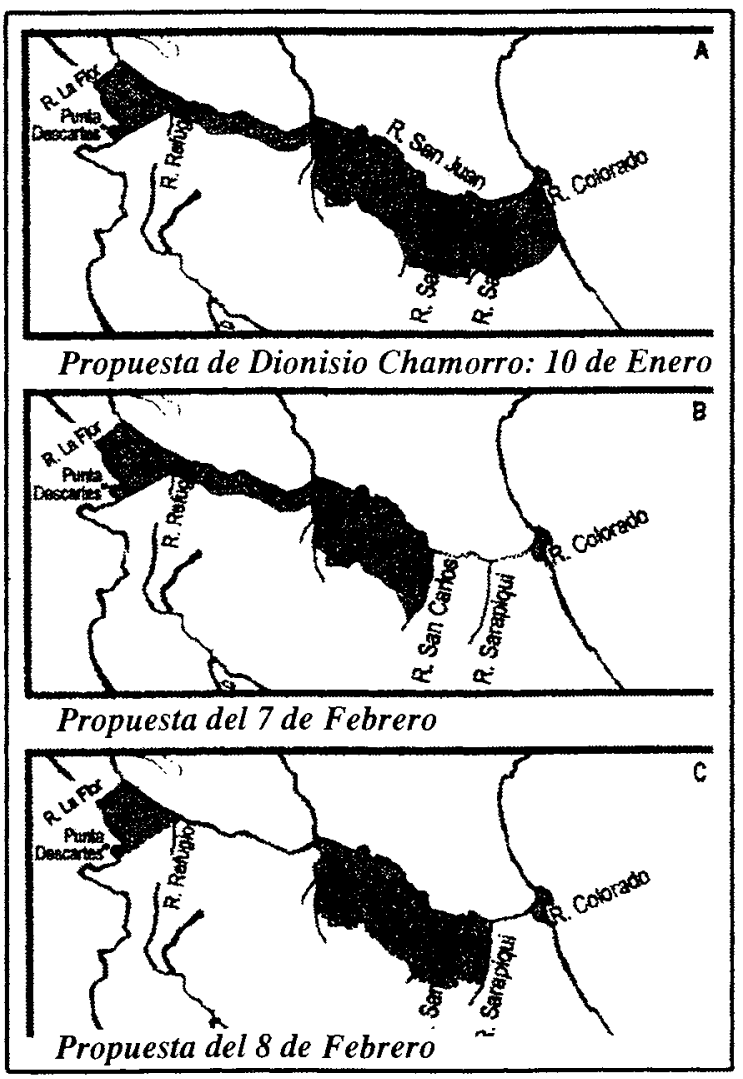

38 del Colorado por su margen derecha (ver Mapa 8, C).

El 9 de febrero, la delegación tica mantenía sus límites, pero cambiaba el trayecto desde el Colorado al mar. Y pedía que las aguas del río y puerto del San Juan fueran libres para su importación y exportación(Mapa 9, C).

Después, el día 13, cambiaba sustancialmente los límites en el Pacífico. Sugería como límites «la Punta de Descartes en el Pacífico, y continuando por la playa meridional de dicha Punta, tomar en línea recta al separarse del mar hacia la desembocadura del río del Refugio en el Lago de Nicaragua, y la ribera de éste al río San Juan». Desde allí seguía igual a la del día 9(ver Mapa

MAPA No. 9

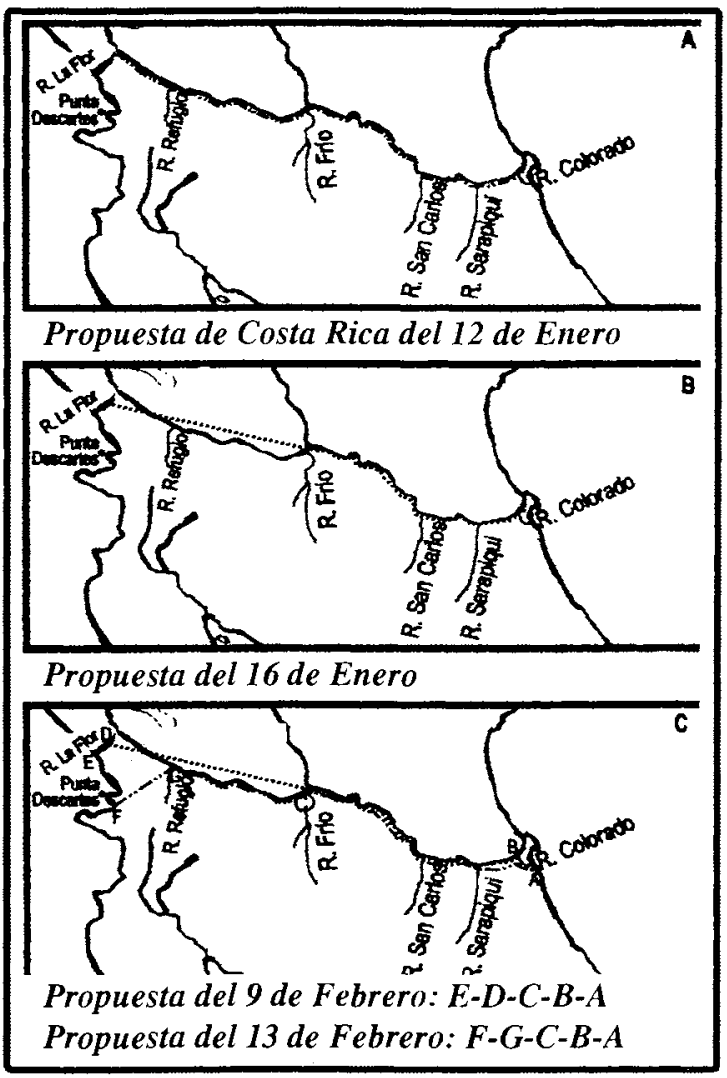


allí seguía igual a la del día 9 (ver Mapa 9, C).

El 17 de febrero don Dionisio fue desconcertante e incongruente. Rechazaba la propuesta tica del día 9 , inadmisible para Nicaragua "por ser contraria a sus intereses y depresiva a su dignidad». Sin embargo, Costa Rica ya había puesto sus fronteras en la margen derecha del Colorado; también, el día 13, había cedido tierra entre el río la Flor y la línea trazada hasta el río Refugio. A esto se añade que Nicaragua, el 8 de febrero, había reformado las propuestas anteriores y aceptado que, desde la confluencia del río Refugio con el lago hasta el río Frío, la ribera del lago fuera el límite con Costa Rica.

La conferencia fracasó y Dionisio Chamorro acusó a Costa Rica de no conformarse con lo concedido por el Congreso Federal y de cercenar el partido de Rivas en la Tortuga y el de Granada en el lago y río San Juan. Al final de la nota amenazó con el uso de la fuerza en la reincorporación de Nicoya. Calvo de Costa Rica contestó a Chamorro y lo criticó de hacer una "declaratoria de guerra». Se tensaron las relaciones y Costa Rica decidió defenderse con las armas si Nicaragua la agredía.

\section{De la Guerra Nacional al tratado Cañas-Jerez}

La Guerra Nacional y los objetivos de Costa Rica

En 1853 Fruto Chamorro asumió el poder y quiso reformar la constitución de 1838 , encontrando tenaz resistencia de la oposición de León y Chinandega. El gobierno decretó la expulsión de los dirigentes democráticos, a quienes se les hizo un "proceso sobre la conspiración que recientemente se tramaba y preparaba en la ciudad de León contra la administración actual del Estado» ${ }^{48}$. Al regresar los expatriados, armas en mano, se inició la guerra civil de 1854 y, el 4 de junio, proclamaron un gobierno provisorio. Luego firmaron el tratado Byron Cole-Castellón y los filibusteros vinieron a Nicaragua poniendo en peligro a Centroamérica. La amenaza se intensificó con la firma del pacto WalkerCorral y se profundizó cuando William Walker, abusando del poder militar, decretó la destitución del Presidente Patricio Rivas por negarle la candidatura a las elecciones presidenciales. En su lugar colocó a Fermín Ferrer quien aceptó su candidatura. Aunque violaba el artículo 130 de la constitución de 1838 , Walker salió elegido presidente en los lugares controlados por él.

Rafael Mora, el presidente de Costa Rica, vislumbró la amenaza y entró en la contienda. Llamó a los nicaragüenses a la reflexión. Al fin, sus recomendaciones y la ambición filibustera lograron que los gobiernos contrincantes firmaran el Pacto Providencial del 12 de septiembre de 1856 y lucharan todos contra Walker. El triunfo definitivo se logró y legitimistas y democráticos establecieron un gobierno provisional, el «Chachagua», en 1857. Tenía dos presidentes, el legitimista Tomás Martínez y el democrático Máximo Jerez.

El 6 de julio de 1857 se firmó en 
Managua el tratado Cañas-Juárez. Nicaragua, en señal de gratitud, entregaba a Costa Rica el Distrito del Guanacaste «para siempre» y señalaba los límites con una línea recta desde el centro de la bahía de Salinas hasta dos leguas, aguas abajo, del Castillo (ver Mapa 10). Para sorpresa de Nicaragua, la Asamblea costarricense no lo ratificó, porque su presidente andaba en negociaciones con los ingleses, como lo confirma el segundo tratado MoraWebster, firmado el 14 de julio. A éste había precedido el primero, de 1856, y a ambos, el Molina-Fyler-Carmichael de 1849. El San Juan, el lago y el río Sapoá estaban presentes en los tres.

El primer Webster-Mora ${ }^{49}$, en su artículo 11 afirmaba que Nicaragua no firmaría tratados de navegación con otros «sin haber procurado antes y obtenido la aprobación del Gobierno de Costa Rica». Mora se basaba en el posible empleo de la fuerza, como lo dejó ver su ministro, cuando el 12 de enero de 1857 notificó al gobierno nica la firma del tratado y le solicitó su adhesión: «Costa Rica que ha contraído un compromiso, que no puede dejar de llenar por su parte, se vería en caso de negativa, forzado a sostenerlo con sus fuerzas, para lo cual no abandonaría sus ventajas en el río y lago ${ }^{50}$.

En el segundo Webster-Mora, Costa Rica hacía concesiones de tierras nicaragüienses como si fueran suyas. Las tierras mencionadas estaban mucho más arriba de los límites señalados en los artículos $1^{\circ}$ y $2^{\circ}$ del Cañas-Juárez. Ante esta realidad, aceptar este tratado, supondría para Costa Rica renunciar a las aspiraciones en el San Juan, lago e istmo de Rivas.

Mora, al entrar en la guerra, no pretendía sólo expulsar al filibusterismo, sino también sacar ventajas territoriales y geopolíticas en la posible victoria. La internacionalización del San Juan y el lago era su objetivo y lo demostró al final de la guerra. Sibaja y Zelaya dicen: «para todos, propios y extraños, se hizo evidente que el gobierno de Mora se quería aprovechar de la ventajosa posición en que había quedado Costa Rica después de la «Campaña del Tránsito», ante una Nicaragua postrada y destruida» ${ }^{51}$. Tal actitud también lo confirmaba el Secretario de Estado, Lewis Cass, en nota a William C. Jones; el 30 de julio de 1857: «Han llegado aquí reportes, los cuales yo espero que no sean correctos, que el gobierno de Costa Rica ha forjado proyectos de engrandecimiento e intenta apropiarse para sí de porciones del territorio de Nicaragua, convirtiendo la guerra que acaba de terminar, con el logro del objeto para que fue declarada, en una treta de adquisición territorial $\gg^{52}$.

Pero existían otras aspiraciones. José María Cañas solicitó a Cornelius Vanderbilt ayuda para fundar un estado independiente en los departamentos de Rivas, Guanacaste y Río San Juan. Esta petición, a pesar de las reservas, Vanderbilt la aceptaría siempre que sacara ventajas en la Ruta del Tránsito ${ }^{53}$. También Cañas recibió una carta, en mayo de 1857, de unos granadinos dispuestos a anexar a Costa Rica los 
partidos de Oriente y Mediodía, si la política interior de Nicaragua no les daba la «suficiente garantía al trabajo y a la propiedad ${ }^{54}$. El lector recordará que en 1843, Toribio Tijerino denunció el intento tico de mandar un agente a Nicaragua con el fin de separar los departamentos de Oriente, Septentrión y del Mediodía del gobierno leonés.

Si el Cañas-Juárez ofreció a Costa Rica «para siempre» el territorio de Nicoya; si Costa Rica ofrecía a Inglaterra, como suyo, el San Juan y el lago; y si su comandancia dio un ultimátum al gobierno nica para que entregara el Fuerte de San Carlos, era porque deseaba más. El ultimátum motivó al Presidente Martínez a responder: "Nicaragua acepta la Guerra que le hace el Gobierno de Costa Rica» ${ }^{55}$. Ante tal respuesta, Mora desistió.

El diálogo suplió a las armas y en Rivas, el 8 de diciembre de 1857, se firmó el tratado Cañas-Martínez. Se acordó devolver a Nicaragua el Castillo Viejo, evacuar el poblado de la Tortuga y reconocer los límites fijados en el CañasJuárez o los antiguos del Partido de Nicoya. Si surgían dificultades, arbitraría un juez nombrado por ambos gobiernos. Costa Rica no lo ratificó.

\section{El tratado Cañas-Jerez y sus consecuencias}

\section{El tratado Cañas-Jerez de 1858}

Ambas repúblicas insistían en la solución de sus conflictos. En enero de 1858, la Asamblea de Nicaragua dispuso que se nombraran comisionados para hacer tratados de paz y límites «sujetos a la ratificación de la Asamblea». El 5 de febrero, ésta autorizó al gobierno a obrar «sin necesidad de ratificación del Poder Lejislativo» ${ }^{56}$. Con tal libertad, Jerez y Cañas firmaron el 15 de abril de 1858 el tratado más importante y conflictivo en la historia de sus límites. Se aceptó que el lago, incluyendo una franja de tierra de dos millas al sur, hasta dos millas aguas arriba del Sapoá, era de Nicaragua; ésta conservaba el territorio entre el río La Flor y el centro de la bahía de Salinas; se trazaron los límites y derechos de Costa Rica y de Nicaragua en el San Juan y quedaron comunes la bahía de Salinas en el Pacífico y la de San Juan del Norte en el Caribe (Mapa 11).

\section{$\operatorname{MAPA} N^{\circ} .11$}

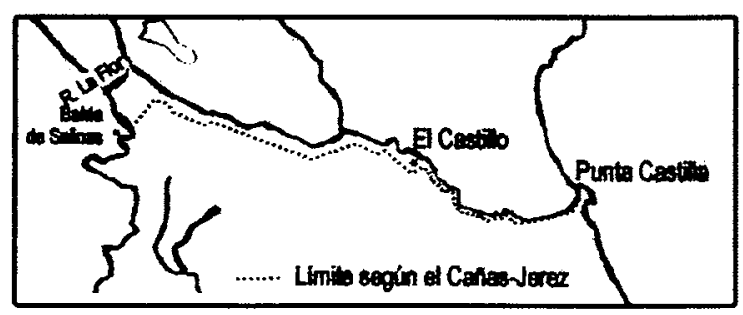

..... Límite según el Cañas - Juárez

Otro punto esencial estaba en el artículo $6^{\circ}$, y quedaba así: "La República de Nicaragua tendrá exclusivamente el dominio y sumo imperio sobre las aguas del río San Juan, desde su salida del Lago hasta su desembocadura en el Atlántico; pero la República de Costa Rica tendrá en dichas aguas los derechos perpetuos de libre navegación, desde la expresada desembocadura, hasta tres millas inglesas antes de llegar al Castillo Viejo con objetos de comercio, ya sea con Nicaragua o al interior de Costa Rica, 
por los ríos de San Carlos o Sarapiquí, o cualquiera otra vía procedente de la parte que en la ribera del San Juan se establece corresponder a esta República. Las embarcaciones de uno u otro país podrán indistintamente atracar en las riberas del río, en la parte en que la navegación es común, sin cobrarse ninguna clase de impuestos, a no ser que se establezcan de acuerdo entre ambos Gobiernos».

El Congreso de Costa Rica lo ratificó al día siguiente. Días después, el 26 de abril en Rivas, el presidente Juan Rafael Mora y Pedro R. Negrete, ministro de El Salvador y mediador del tratado, firmaron con el presidente Martínez el acta de canje. Pero, aunque la asamblea de Nicaragua permitía al ejecutivo hacer arreglos sin necesidad de ratificación, el propio tratado la exigía «dentro de cuarenta días de la signatura, en Santiago de Managua» (Art. 12). Y aunque Martínez firmó el canje, la asamblea sólo lo aprobó el 4 de junio de 1858 (se lee «apruébase», y no ratifíquese).

\section{Primeros conflictos}

Entre 1858 y 1871 el tratado fue reconocido como válido por Costa Rica y con reservas por Nicaragua. La actitud negativa de Nicaragua llevó a Costa Rica a emprender nuevas negociaciones que desembocaron en la convención ZelayaVolio del 13 de julio de $1868^{57}$. Se pretendía hacer obras en el río San Juan y en el Colorado y ver de cuál de ellos convenía echar las aguas al otro para mejorar uno de los puertos. Meses después, en diciembre, se suscribía la convención Rivas-Esquivel adicional a la anterior, en la que Costa Rica concedía a Nicaragua las aguas del Colorado para mejorar el puerto de San Juan. En su artículo $6^{\circ}$ el gobierno de Nicaragua ratificaba «los Tratados que tienen celebrados sobre límites con el gobierno de Costa Rica; y ambas partes se someten al Arbitraje del gobierno de los Estados Unidos de Norte América para la decisión de cualquier cuestión que se suscite ya sobre aquéllos Tratados o bien sobre la ejecución del presente convenio».

El 21 de junio de 1869, en San José, relacionado con la desviación de las aguas del Colorado, se firmó el tratado Jiménez-Montealegre «para completar la Convención» del 13 de julio. El artículo $6^{\circ}$ insistía en que Nicaragua ratificaba "los tratados que tiene celebrados sobre límites con el Gobierno de Costa Rica». No importaba a esta república ceder las aguas del Colorado con tal que se ratificara y tuviera validez el CañasJerez.

El día 6 de octubre de 1868 , se firmó en París el tratado canalero Ayón-Chevalier. Fue ratificado en Managua el 15 de marzo de 1869. Poco después, Mariano Montealegre de Nicaragua y Agapito Jiménez de Costa Rica, el 18 de junio de 1869, firmaron en San José el «Tratado sobre Canalización Interoceánica entre Nicaragua y Costa Rica». El artículo 1 dejaba en claro su apoyo al AyónChevalier: «La República de Costa Rica se adhiere al contrato celebrado en París». Este tratado Jiménez- 
Montealegre fue aprobado y ratificado por la legislatura de Costa Rica.

Un año después, el 27 de abril de 1870 , el general Tomás Guardia dio un golpe de estado, tomó el poder, desconoció el tratado Ayón-Chevalier y por decreto declaró insubsistente el JiménezMontealegre. Este acontecimiento desembocó en lo esperado. Tomás Ayón, en la memoria al Congreso, negó toda validez del tratado Cañas-Jerez alegando la falta de ratificación en la legislatura de 1859 . El $1^{\circ}$ de febrero de 1871 , el secretario de relaciones exteriores de Costa Rica refutó a Ayón. Se pasó a discusiones que acabaron cuando el presidente Cleveland, en su alegato de 1888, sentenció su validez. Sin embargo, antes de esta sentencia aún habían de promulgarse algunos documentos.

\section{De Vicente Cuadra a Cleveland}

Don Vicente Cuadra, en 1871, declaró nulo el tratado Cañas-Jerez. Cuando el gobierno tico se enteró, su presidente invitó al de Nicaragua a reunirse y lo hicieron en Rivas en 1872. El presidente Guardia declaró: "Que él reconocía que las anteriores administraciones de la República de Costa Rica habían tenido una política muy mezquina, emprendiendo disputas por un pedazo de terreno despoblado e inculto; pero que él había roto con ese pasado, estableciendo una política liberal y desinteresada, en la convicción de que estos dos países están llamados a confundir sus grandes intereses, único modo de establecer la unión nacional $\aleph^{58}$. A continuación el presidente Cuadra expuso el juicio que el pueblo nicaragüense tenía sobre el Cañas-Jerez. Guardia solicitó un nuevo proyecto de arreglo y Vicente Cuadra aceptó de inmediato. Ambos nombraron sus representantes.

Vicente Herrera representaba a Costa Rica y, lejos de corroborar lo convenido, manifestó que su gobierno pretendía obtener sus límites naturales, es decir, toda la margen derecha del San Juan y del lago hasta el Sapoá y desde allí hasta la bahía de Salinas ${ }^{59}$ (Ver mapa 10). La negociación fracasó porque Nicaragua no aceptó tal proposición. Ante el fracaso, el presidente Guardia reaccionó violentamente. Fingiéndose enfermo salió a curarse rumbo a Europa. Emilio Benard, Ministro de Nicaragua en Washington, escribió a don Vicente poniéndole al tanto de la enfermedad de Guardia: Que salía para Europa «en busca de salud..., pero que el objeto del viaje» era diferente, pues quería conseguir un empréstito. «Que Guardia estaba negociando dos mil Remington con considerable cantidad de parque...» y que «si fuese necesario pondría inmediatamente CIEN MIL ALEMANES y todos los recursos necesarios ${ }^{60}$.

Cuadra siguió fiel a su palabra y Guardia envió a Nicaragua a Ramón Tinoco y P. Salamanca con 22.000 pesos oro con el pretexto de comprar ganado, pero con la finalidad de comprar conciencias. Al no lograr nada, el gobierno tico promovió una alianza intercentroamericana contra Nicaragua. 
A Vicente Cuadra lo sucedió Pedro Joaquín Chamorro, quien tuvo que enfrentarse al partido liberal y a algunos conservadores. Máximo Jerez llegó al Guanacaste para invadir Nicaragua. El gobierno de Guardia expidió el acuerdo del 25 de marzo de 1876, apoyando al partido liberal y estipulando con los Jefes de éste, previamente, el reconocimiento de los límites naturales de Costa Rica en el Lago y Río San Juan en toda su extensión ${ }^{61}$.

Lo exigido era lo ya expresado por Vicente Herrera en Rivas, en tiempos de Cuadra. Nicaragua lo rechazó entonces y ahora. Al no lograr sus objetivos, el gobierno de Guardia, por decreto del 14 de noviembre de 1876, rompió «las relaciones oficiales y comerciales», las que se reactivaron por el decreto del 30 de junio de $1878^{62}$.

Nuevas negociaciones: 1882-1887

En 1882 Costa Rica y Nicaragua volvieron a las negociaciones de límites. $Y$ el 5 de febrero de 1883, firmaron en Granada el tratado Alvarez-Zambrana. Acordaron que la frontera era la margen derecha del Colorado, y desde la confluencia de éste con el San Juan se extendía hasta un punto distante del Castillo tres leguas inglesas (Art. $1^{\circ}$ ), y lo demás quedaba como en el CañasJerez. Aceptaron también los derechos de Costa Rica a la navegación comercial en las aguas del lago y ríos San Juan y Colorado «correspondiendo a Nicaragua el dominio eminente y sumo imperio sobre los dichos ríos y Lago». Costa Rica no lo ratificó.
El 19 de enero de 1884 se suscribió en San José el tratado Navas-Castro. El artículo $1^{\circ}$ era muy similar al del tratado anterior. El $5^{\circ}$ expresaba que en caso de desvío de las aguas del Colorado «sobre el San Juan, la ribera derecha de éste hasta tres millas inglesas antes de llegar al Castillo Viejo será la primera parte de la línea de límites, en lugar de la margen derecha del Colorado, estipulada en el artículo $I$.». Tampoco fue ratificado.

El tan deseado arreglo llegó el 24 de diciembre de 1886. Ascensión Esquivel de Costa Rica y José Antonio Román de Nicaragua, con la presencia del ministro guatemalteco, don Fernando Cruz, firmaron en Guatemala «La Convención Arbitral de límites entre Nicaragua y Costa Rica» (Román-Esquivel-Cruz). Acordaron someter el Cañas-Jerez a un «arbitramento» $\left(\right.$ Art. $1^{\circ}$ ) y determinaron que el árbitro fuera «el señor Presidente de los Estados Unidos de América» (Art. $2^{\circ}$ ). Esta convención la aprobó el gobierno de Adán Cárdenas el 28 de enero de 1887. El acta de canje se firmó en Managua el $1^{\circ}$ de junio de 1887 por don Federico Solórzano y don Faustino Víquez, plenipotenciarios nombrados «ad Hoc». Luego se decretó como ley de la república.

\section{Del laudo Cleveland a los laudos Alexander}

Conforme a lo estipulado en la convención Román-Esquivel-Cruz, el presidente de los Estados Unidos de América, Grover Cleveland, promulgó su laudo el 22 de marzo de 1888. De esta 
manera quedó solucionado el tan debatido tema fronterizo. La sentencia daba por válido el tratado Cañas-Jere $z^{63}$. El artículo $7^{\circ}$ del Román-Esquivel-Cruz consideraba que este laudo era inapelable y el $10^{\circ}$ mandaba que, si el presidente de Estados Unidos lo declarara válido, se debía nombrar una comisión para medir y amojonar el espacio dentro de los treinta meses. Pasó el tiempo sin medir nada, y los gobiernos litigantes, el 9 de diciembre de 1891, firmaron en Managua el tratado Guerra-Castro. Su artículo $1^{\circ}$ ordenaba abrir otro plazo de treinta meses, a partir del $1^{\circ}$ de enero de 1892 , para efectuar las medidas prescritas. A la vez, se hicieron algunas modificaciones fronterizas del tratado Cañas-Jerez, en la bahía de Salinas.

Transcurrió el tiempo y no se amojonó. Entonces el 27 de marzo de 1896, en San Salvador, se suscribió la convención Matus-Pacheco. Ambos gobiernos se obligaban a nombrar separadamente una comisión de dos ingenieros o agrimensores para trazar y amojonar la línea fronteriza, de acuerdo al CañasJerez y al laudo Cleveland (Art. 1). El presidente de Estados Unidos nombraría a otro ingeniero en calidad de árbitro que tendría «amplias facultades para decidir cualquiera clase de dificultades» si surgían, y "conforme a su fallo» se ejecutarían las operaciones (Art. 2). Cleveland nombró ingeniero-árbitro a E.P. Alexander, quien, entre el 30 de septiembre de 1897 y el 24 de junio de 1900 , promulgó los 5 laudos y el acta final de la obra realizada por la comisión de límites. Esta comisión tomó en cuenta un sinnúmero de meticulosidades, como la de considerar si el río estaba o no crecido, si había inundaciones, etc. El trabajo se realizó con mucha seriedad. Por fin, quedaron definitivamente marcadas las fronteras entre ambas repúblicas, tal como hoy teóricamente están.

\section{Epílogo}

Estas son, a grandes rasgos, algunas de las vicisitudes fronterizas entre Nicaragua y Costa Rica. El tratado Cañas-Jerez y el laudo Cleveland sentaron las bases definitivas para las medidas y el amojonamiento del ingeniero Alexander.

Pero hoy siguen los problemas. No obstante, hay que delimitar dos aspectos. Uno se refiere a los temas fronterizos, geográficos; otro, más jurídico, puede ser la determinación de cuáles son los derechos de ambas naciones en la navegación y comercialización.

En cuanto al primer aspecto, objeto de este trabajo, geógrafos e historiadores coinciden en que el río San Juan es de Nicaragua. Las fronteras fueron definidas y ambas naciones aceptaron el laudo Cleveland y las demarcaciones de Alexander. Acaso haya que reponer los mojones desaparecidos. Actualmente la desembocadura del río San Juan no es idéntica a la de 1900 , lo que presupone que ambas repúblicas deben negociar para aclarar lo que el tiempo, las aguas y la sedimentación han borrado o cambiado. Pero el conflicto debe reducirse a ese punto y no extenderlo al resto del río. Este hecho no debe 
desvirtuar la realidad geográfica: el río Concluyo con una idea de «La San Juan está en territorio de Nicaragua. República», citada en «La Noticia»: «Nicaragua tiene el dominio y sumo En cuanto al segundo aspecto, que imperio» sobre el San Juan, y en discutan los juristas del derecho consecuencia Costa Rica sólo tiene internacional y que interpreten el Cañas- derecho de navegación «estrictamente Jerez y el laudo Cleveland y determinen comercial». Por eso cualquier acuerdo qué eran antes y qué son actualmente los «objetos de comercio» o si está de acuerdo con los tratados que la vigilancia de Costa Rica pueda o no navegar armada por el río San Juan para avituallar sus puestos fronterizos. sobre las pretensiones de la guardia de Costa Rica de navegar armada sobre el río «depende exclusivamente de la voluntad nicaragüense ${ }^{64}$. 


\section{Notas}

'Vega Bolaños, Andrés: "Documentos para la Historia de Nicaragua", Tomo I, LV, pp.249253.

${ }^{2}$ Fernández, León: "Colección de documentos...", Tomo IV, p. 28 (Texto completo: pp. 2334). Acentúa la demarcación con Honduras y la salida de Nicaragua a un puerto en el mar del Norte.

${ }^{3}$ Sibaja, Luis Fernando: (1997) Nuestro límite con Nicaragua: Estudio histórico"22, San José, p. 46.

${ }^{4}$ Fernández Guardia, Ricardo. (1933) Historia de costa Rica, Librería Alsina, pp. 67-71. Sintetiza documentos de León Fernández.

5Fernández, León: "Colección de documentos...", Tomo IV, pp. 90-96. El documento confunde Aguán y el Desaguadero.

${ }^{6}$ Fernández, Guardia: "Historia de Costa...," Tomo I, p.99.

'Peralta, Manuel de: Costa Rica, Nicaragua y Panamá en el Siglo XVI, pp. 120-122.

${ }^{8}$ Vega Bolaños, Andres. "Documentos...", Tomo VII, CDXCII, p.29.

${ }^{9}$ Peralta: “Costa Rica...", pp. 120-122.

${ }^{10}$ Peralta: “Costa Rica...", pp. 125-127.

"Peralta, Manuel de: (1898) Exposé des droits territoriaux de la République de Costa Rica, soumis a S: E. M. le président de la République Française, arbitre de la question des limites, París, pp. 45-46.

${ }^{12}$ Peralta,: Costa Rica..., pp. 194-195.

${ }^{13}$ Peralta, Manuel de. (1898) Límites de Costa Rica y Colombia. Nuevos documentos para la historia de su jurisdicción territorial, con notas, comentarios y un examen de la Cartografía de Costa Rica y Veragua, Madrid, p. 10.

${ }^{14}$ "Colección de documentos inéditos relativos al descubrimiento, conquista y organización de las antiguas posesiones españolas en América y Oceanía, sacados de los archivos del reino especialmente del de las indias", (1875) Madrid, Imprenta de Manuel G. Hernández, Tomo XXIII. (Texto completo, pp. 171-189).

${ }^{15}$ Meléndez Chaverri, Carlos: "La verdad histórica en torno a la anexión del partido de Nicoya a Costa Rica", en Informe Semestral del Instituto Geográfico Nacional, San José.

${ }^{16}$ Revista de los archivos nacionales de Costa Rica (RANCR), mayo y junio de 1937, año I, $\mathrm{N}^{\circ}$ s. 7-8. Texto completo pp. 356-369.

${ }^{17}$ RANCR, set-oct de 1939, año III, ${ }^{\circ}$ s. 11-12, pp. 579-281.

${ }^{18}$ Puede verse Esgueva, Antonio: (1995) "Las Leyes Electorales en la Historia de Nicaragua”, Editorial Nuevo Amanecer, Tomo I, Docs. $N^{\circ} 2$ y 4 respectivamente.

${ }^{19}$ Sibaja-Zelaya: O.C., p. 53

${ }^{20}$ RANCR, julio-agosto de 1937, año I, Nº. 9-10. Con Granada en las pp 461-463 y con León en las 466-469.

${ }^{21}$ Alvarez, Miguel A. (1942) De cómo perdimos las provincias de Nicoya y Guanacaste, Escuela Tip. Salesiana, Granada, p. 11

${ }^{22}$ Zelaya Goodman, Chester: Nicaragaua en la Independencia, Educa, pp. 236-241.

${ }^{23}$ Transcrito por Sibaja-Zelaya, O.C., Doc. 3, p. 143.

${ }^{24}$ A.N.C.R., Sec. Adm. Arch. Gobern., Exp. 8445, f. 14. (Citado por Sibaja-Zelaya, O.C., p. 66).

${ }^{25}$ Texto en Zelaya Goodman: “Nicaragua...”, Doc. $\mathrm{N}^{\circ} 15$ 
${ }^{26}$ Montúfar, Lorenzo: Reseña Histórica de Centroamérica", Tomo IV, p. 382.

${ }^{27}$ Pasos Argüello: (1982) Los conflictos internacionales de Nicaragua, Col. Cultural del Banco de América, p. 13.

${ }^{28}$ Obregón Quezada, Clotilde: (1993) El río San Juan en la lucha de las potencias: 18211860”, ed. Universidad estatal a distancia, San José,p. 47

${ }^{29}$ Transcrito por Sibaja-Zelaya, O.C., Doc. $\mathrm{N}^{\circ} 6$

${ }^{30}$ Transcrito por Sibaja-Zelaya, O.C., Doc. N ${ }^{\circ} 7$, p. 150.

${ }^{31}$ Montúfar, Lorenzo: "Reseña...", Tomo VII, p.15.

${ }^{32} \mathrm{RANCR}$, marzo-abril de 1939, año III, N s. 5-6. Las primeras instrucciones en las páginas 328-330; las reservadas, en las $330-332, \mathrm{~N}^{\circ}$ s. $1^{\circ}$ y $8^{\circ}$.

${ }^{33}$ Alvarez, M. A., O. C., p. 21.

${ }^{34}$ Alvarez M. A., O. C., p. 24-25.

35"Cuenta documentada del comisionado del supremo gobierno de Nicaragua cerca del de Costarrica sobre la obligación que el segundo tiene de devolver al primero el partido de Nicoya" (Doc. $\mathrm{N}^{\circ} 11$ ). En este folleto está todo lo relacionado con las negociaciones de don Toribio Tijerino.

${ }^{36}$ Obregón, Clotilde: (1993) El río San Juan en la lucha de las potencias (1821-1860), Editorial Universidad estatal a distancia, San José, pp. 85-86.

37"Conferencias habidas entre los comisionados de Costa Rica y Nicaragua sobre la anexión del partido de Nicoya al primero de los estados y límites territoriales de uno y otro, mandadas publicar de orden del supremo gobierno de Nicaragua", año 1828, imprenta La Paz.

${ }^{38}$ RANCR, 1988..., p. 223, $\mathrm{N}^{\circ} 43 \mathrm{a}$

${ }^{39}$ Citado por Bolaños Geyer, Alejandro: (1998) “San Juan de Nicaragua”, Banco Central de Nicaragua, Septiembre, p. 15.

${ }^{40}$ RANCR, 1988, año LII, Nos. 1-12, pág. 210, No. 17a

${ }^{41}$ RANCR, $1988 \ldots$, pág. $226-228$, No 53 y pág. $234-240, \mathrm{~N}^{\circ} 77 \mathrm{a}$

${ }^{42}$ Montúfar, L.: "Reseña..." Tomo IV, cap. XXVI, p. 170.

${ }^{43}$ Montúfar, L.: "Reseña...", Tomo VI, cap. XXVI, p. 171.

${ }^{44}$ Esgueva, A. "Documentos...”, Doc. No 91, pp. 215-218.

${ }^{45}$ Pasos Argüello, Luis: (1976) Canalización conjunta del río San Juan, Editorial Unión, p. 17

${ }^{46}$ Este río no he podido encontrarlo, por lo que su representación en el mapa no es objetiva. Sin embargo, he preferido imaginarlo en algún lugar para que a partir de ahí se puedan entender mejor las diferentes negociaciones.

${ }^{47} \mathrm{Las}$ diferentes citas relacionadas con estas negociaciones pueden encontrarse en "El Protocolo de conferencias sobre límites entre los plenipotenciarios de Costa Rica y Nicaragua ( 10 de enero al 17 de febrero de 1854)'. Están publicadas en la RSGHN, Vol. XI, N², enero-marzo de 1952, desde la p. 135.

${ }^{48}$ Pérez, Jerónimo: "Obras históricas completas", Col. Cultural del Banco de América, Serie Histórica, $\mathrm{N}^{\circ} 5$, pp. 345-347.

${ }^{49}$ Woodbridge, Paul: (1967) “Los Contratos Webster-Mora”, Editorial Costa Rica, . El primero en las pp. 45-55; el segundo, en 59-70.

${ }^{50}$ Citado por Bolaños Geyer. O.C., p.34.

${ }^{51}$ Sibaja-Zelaya, O.C., pp. 118.

${ }^{52}$ A.N.C.R., Sec. Adm. Arch. Relac. Ext. Caja N 31, pág. 95-98. (Citado Sibaja-Zelaya, O.C., p. 118). 
${ }^{53}$ Woodbridge, Paul. Los Contratos..., Doc. VIII p. 85-86.

${ }^{54}$ Woodbridge Paul: Los Contratos..., p. 71-72

${ }^{55}$ Pasos Argüello: Canalización... Ambos documentos en las pp. 43-44 y 45-46.

${ }^{56} \mathrm{De}$ la Rocha, J. "Código de la legislación de Nicaragua", Tomo I, Libro II, Título I. Ambos son las leyes 6 y 7 , pp. 92 y 93 .

${ }^{57}$ Bonilla, J. M.: Derecho de Gentes.... En el mismo libro se encuentran los tratados que menciono más adelante: Zelaya-Volio; Rivas-Esquivel; Jiménez-Montealegre; AlvarezZambrana; Navas-Castro; Román-Esquivel-Cruz; Guerra-Castro; y Matus -Pacheco.

${ }^{58}$ Escobar, Esteban: "Pedro Joaquín Chamorro: Biografía" en RPCA, No. 92, Mayo de 1966, pág. 29).

${ }^{59}$ Escobar, Esteban: O. C., p. 29.

${ }^{60}$ Alvarez, M. A., O. C., p. $75-79$

${ }^{61}$ Citado por Pasos Argüello: Canalización..., pp. 73-74.

${ }^{62}$ Memorias de Relaciones Exteriores, 1897, pp. 23-24.

${ }^{63}$ Memorias de Relaciones Exteriores, 1916, pp. 346-349.

${ }^{64}$ Diario "La Noticia, Managua, 17 de Marzo del 2000, pág.2-B. El título es: “Tienen tan buenos argumentos como Nicaragua. Hasta los ticos saben que no deben meterse en el San Juan". 